\title{
A (IR) RACIONALIDADE NA JUSTIFICAÇÃO DAS DECISÕES JUDICIAIS COMO FATOR DETERMINANTE PARA A IDENTIFICAÇÃO DO PRECEDENTE VINCULANTE ${ }^{1}$
}

\section{(IR) RATIONALITY IN THE JUSTIFICATION OF JUDICIAL DECISIONS AS A DETERMINING FACTOR FOR THE IDENTIFICATION OF THE BINDING PRECEDENT}

Doutoranda em Direito pela Universidade de Brasília (UNB). Mestre em Direito Processual pela Universidade do Estado do Rio de Janeiro (UERJ). Bacharel em Direito pela Universidade Federal de Juiz de Fora (UFJF). Membro da Associação Brasiliense de Direito Processual Civil (ABPC). Brasília/DF. E-mail: tatianapaulacruz@gmail.com

RESUMO: O trabalho busca analisar a relevância da identificação da ratio decidendi na aplicação do precedente judicial, apresentando a dificuldade no exercício desta tarefa, diante da carência de racionalidade argumentativa das decisões proferidas por Tribunais Superiores. O raciocínio será demonstrado a partir da aplicação do modelo de análise argumentativa proposto por Stephen Toulmin ao julgamento recente proferido pelo STF no bojo do Recurso Extraordinário nº 1.116.949/PR.

PALAVRAS-CHAVE: Precedentes; argumentação jurídica; racionalidade; fundamentação; ratio decidendi.

ABSTRACT: The study seeks to analyze the relevance of identifying the ratio decidendi in the application of the judicial precedent, presenting the difficulty in carrying out this task, in the face of the lack of argumentative rationality in the decisions handed down by Superior Courts. The reasoning will be demonstrated from the application of the argumentative

\footnotetext{
${ }^{1}$ Artigo recebido em 30/01/2021 e aprovado em 25/03/2021.
} 
analysis model proposed by Stephen Toulmin to the recent judgment given by the STF within the scope of extraordinary resource number 1.116.949 / PR.

KEYWORDS: Precedents; legal reasoning; rationality; reasoning; ratio decidendi.

\section{Considerações iniciais sobre a identificação da ratio decidendi na aplicação do precedente judicial}

A ideia de seguir precedentes judiciais é mais familiar para países de cultura anglosaxônica do que para aqueles de origem romano-germânica. A doutrina tradicional do civil $l a w^{2}$ sempre reconheceu que a centralidade do sistema se encontrava na lei. Isso porque, com a codificação, a crença na completude fez com que as soluções jurídicas sempre fossem buscadas na letra da lei, reduzindo, ao máximo, o poder interpretativo do juiz. Nos países integrantes da família do common law, por sua vez, a regra do direito deriva da jurisprudência (o case law, como reconhecido no direito inglês). A partir de um julgamento de um caso paradigmático, pode-se dissecar a decisão e buscar naquela a razão determinante (ratio decidendi), afastando aquilo que não contribuiu diretamente para a solução do caso (obiter dictum $)^{3}$.

Contudo, a aproximação entre os sistemas jurídicos é uma realidade, altamente influenciada pelo constitucionalismo nos países de civil law, já há muito reconhecida e explorada pela doutrina brasileira ${ }^{4}$, tendo havido um acréscimo do poder criativo do magistrado. O Código de Processo Civil de 2015, degrau mais recente na escalada rumo à valorização do precedente judicial, incorporou ao direito positivo novas situações em que alguns precedentes irradiam efeitos vinculantes, destacando-se o inédito incidente de resolução de demandas repetitivas e o fortalecimento dos recursos especial e extraordinário repetitivos.

\footnotetext{
${ }^{2}$ René David. DAVID, René. Tradução Hermínio A. Carvalho. Os grandes sistemas do direito contemporâneo. 4 ed. São Paulo: Martins Fontes, 2002.

${ }^{3}$ FINE, Toni Jaeger. Introdução ao sistema jurídico anglo-americano. Tradução Eduardo Saldanha. São Paulo: Martins Fontes, 2011.

${ }^{4}$ MARINONI, Luiz Guilherme. Aproximação crítica entre as jurisdições de civil law e de common law e a necessidade de respeito aos precedentes no Brasil. Revista de Processo, São Paulo, a. 34, n. 175, p. 182, jun.2009.
} 
Se os precedentes vinculantes se tornaram uma realidade no direito brasileiro, mostra-se indispensável o estudo de sua identificação para que, na prática, seja possível concluir o que vincula em uma decisão judicial.

Neil Dexbury traz uma premissa fundamental para o estudo da ratio ao reconhecer que satisfaz muito pouco dizer que a essência da decisão judicial deve ser encontrada olhando para as razões que suportam essa decisão, já que um mesmo julgamento é composto de diversas razões, dos mais variados graus de importância; em muitos casos, existem partes do raciocínio judicial que não integram a ratio, mas configuram obiter dictum, ou seja, aquilo que foi dito meramente de passagem ${ }^{5}$. O que muito importa definir é a essência da decisão, indispensável para explicar o resultado do julgamento, mas, na grande maioria das vezes, esta regra essencial não vem descrita expressamente na própria decisão, apenas é desvendada em um caso futuro, quando aquele precedente pretende ser aplicado ${ }^{6}$.

A parte vinculante da decisão, chamada pelos anglo-saxônicos de ratio decidendi, é essa essência da decisão, indispensável para explicar o resultado do julgamento. Uma vez definida a ratio, será possível encontrar as circunstâncias que não foram essenciais ao julgamento da causa e que, uma vez excluídas, não levariam à alteração da decisão. Nisso consiste o obiter dictum, ou "dito para morrer", em sua literalidade. Definir a ratio se faz por meio de argumentação, cujo controle se dá na fundamentação ${ }^{7}$.

O problema, como bem constatam Fabio Schecaira e Noel Struchiner ${ }^{8}$, é que as decisões judiciais não anunciam normas jurídicas da mesma maneira concisa como fazem as leis e são, na maioria das vezes, técnicas, longas e maçantes, tornando mais difícil a identificação da parte efetivamente vinculante.

A essa dificuldade natural de identificação da ratio, soma-se um problema comum no Brasil apontado por Claudia Roesler ${ }^{9}$. Trata-se da constatação de que as decisões

\footnotetext{
${ }^{5}$ DUXBURY, Neil. The nature and authority of precedent. Cambridge: University Press, 2008, p. 67-68. Ainda Segundo Rupert Cross, de maneira precisa: "the ratio 'is any rule of law expressly or impliedly treated by the judge as a necessary step in reaching his conclusion, having regard to the line of reasoning adopted by him". CROSS, Rupert. HARRYS, J. W. Precedent in English Law. Oxford: Clarendon Press, 2004, p. 72.

${ }^{6}$ WAMBIER, Teresa Arruda Alvim. Precedentes e evolução do direito. in WAMBIER, Teresa Arruda Alvim (coord.). Direito Jurisprudencial, São Paulo: Revista dos Tribunais, 2012, p. 44.

${ }^{7}$ MACÊDO, Lucas Buril. Contributo para definição da ratio decidendi na teoria brasileira dos precedentes judiciais. Revista de Processo, São Paulo, SP, V. 234, ago. 2014, p. 312.

${ }^{8}$ SHECAIRA, Fábio P; STRUCHINER, Noel. Teoria da Argumentação Jurídica. Rio de Janeiro: Editora PUC Rio, 2016, p. 125.

${ }^{9}$ ROESLER, Entre o paroxismo de razões e a razão nenhuma: paradoxos de uma prática jurídica. Quaestio Iuris, vol. 8, n. 4, 2015, p. 2517-2531.
} 
colegiadas muitas vezes não são verdadeiras decisões construídas pelo colegiado e sim um amontoado de várias decisões produzidas previamente nos gabinetes dos ministros. Essa reunião de votos prontos torna ainda mais difícil entender quais foram as razões de decidir, já que cada julgador fundamenta seu voto em sua percepção prévia, tomada de antemão, quando da análise do caso pelo gabinete.

A autora aponta, em síntese, a tendência dos tribunais superiores de recorrer a argumentos legais em casos considerados "fáceis" e partir para julgamentos eruditos e extensos em casos considerados "difíceis", como se o argumento de autoridade fosse sempre a lei ou a doutrina ${ }^{10}$.

Neste ponto, recorrendo aos estudos de Toulmin ${ }^{11}$, parece possível afirmar que, em casos fáceis, os Tribunais Superiores se valem da lógica dedutiva reducionista e outras vezes produzem decisões baseadas em um amontoado de argumentos provenientes de diversos votos pré-formatados, que impedem a identificação da real razão de decidir, fragilizando sobremaneira o julgado.

O esquema proposto por Toulmin ${ }^{12}$ é apenas um dos modelos possíveis para análise da racionalidade das decisões judiciais, sendo exposto por Ângelo Gamba Prata de Carvalho ${ }^{13}$ como uma ferramenta importante para identificar as razões de decidir e os obiter dicta, permitindo um vislumbre sobre qual parte da decisão judicial é capaz de gerar precedentes que orientem outros casos semelhantes.

Este estudo propõe a análise de uma decisão judicial proferida recentemente pelo Supremo Tribunal Federal, segundo o modelo acima descrito, buscando avaliar, na prática, se a identificação da ratio decidendi efetivamente torna-se mais difícil pela falta de racionalidade do julgado.

\footnotetext{
${ }^{10}$ ROESLER, Entre o paroxismo de razões e a razão nenhuma: paradoxos de uma prática jurídica. Quaestio Iuris, vol. 8, n. 4, 2015, p. 2517-2531.

11 TOULMIN, Stephen. The Uses of Argument. Updated Edition. Cambridge: Cambridge University Press, 2003. Tradução para o português: Os Usos do Argumento. Trad. de Reynaldo Guarani. São Paulo: Martins Fontes, 2001.

12 TOULMIN, Stephen. The Uses of Argument. Updated Edition. Cambridge: Cambridge University Press, 2003. Tradução para o português: Os Usos do Argumento. Trad. de Reynaldo Guarani. São Paulo: Martins Fontes, 2001.

13 CARVAlHO, Angelo Gamba Prata de. O esquema de Toulmin e a análise argumentativa de decisões judiciais: perspectivas a partir e além de "Harry nasceu nas Bermudas". In: ROESLER, Claudia; HARTMANN, Fabiano; REIS, Isaac (Orgs.) Retórica e argumentação jurídica: modelos em análise. Curitiba: Alteridade, 2018, p. 62.
} 
Para os fins do presente trabalho, interessa especialmente entender que a ratio decidendi, como bem definiu Paulo Alves Santos ${ }^{14}$, é o argumento central do julgamento que, uma vez referendado pelo Tribunal, será o precedente a ser utilizado em decisões jurídicas futuras.

\section{Aplicação do modelo de Toulmin ao julgamento proferido no recurso extraordinário}

\subsubsection{9/PR}

\subsection{Breves considerações sobre o esquema de análise argumentativa de Toulmin}

O modelo de Toulmin será utilizado apenas como um exemplo de método de interpretação da decisão a partir dos argumentos jurídicos nela expostos, de modo a verificar a racionalidade da decisão.

Para tanto, vale lembrar que Stephen Toulmin desenvolve sua análise argumentativa em um contexto de superação da lógica formal dedutiva que, segundo ele, seria reducionista ao entender que a validade de um argumento dependeria apenas do preenchimento de critérios formais e do recurso a critérios matemáticos e absolutos. Para o filósofo, a lógica depende da análise do conteúdo da argumentação que se faz e da solidez dos argumentos ${ }^{15}$.

O objetivo de Toulmin vai ao encontro de uma inquietação presente na análise de Noel Struchiner sobre os contextos de descoberta e justificação. O primeiro diz respeito aos fatores sociológicos e históricos que explicam como o cientista chegou a determinada teoria, enquanto o segundo, diz respeito à maneira como ele irá justificá-la diante da comunicada científica ${ }^{16}$.

Da análise de Struchiner, fica claro que o que se faz no direito é racionalizar decisões, sendo estas, em verdade, tomadas com recurso a elementos não necessariamente jurídicos.

\footnotetext{
${ }^{14}$ SANTOS, Paulo Alves. Usando precedentes no layout de argumento proposto por Stephen Toulmin. In: ROESLER, Claudia; HARTMANN, Fabiano; REIS, Isaac (Orgs.) Retórica e argumentação jurídica: modelos em análise. Curitiba: Alteridade, 2018, p. 285.

${ }^{15}$ TOULMIN, Stephen. The Uses of Argument. Updated Edition. Cambridge: Cambridge University Press, 2003. Tradução para o português: Os Usos do Argumento. Trad. de Reynaldo Guarani. São Paulo: Martins Fontes, 2001.

${ }^{16}$ SHECAIRA, Fábio P; STRUCHINER, Noel. Teoria da Argumentação Jurídica. Rio de Janeiro: Editora PUC Rio, 2016, p. 155.
} 
A inquietação presente no estudo deste autor diz respeito à necessidade de que as decisões débeis, aquelas tomadas primordialmente a partir da emoção, sejam identificadas ${ }^{17}$.

Se muitas vezes o contexto de descoberta pressiona o contexto de justificação, parece necessário que o estudo da argumentação jurídica tenha como norte a busca de uma teoria capaz de identificar quando a decisão é justificável sistemicamente e quando sua racionalidade é questionável, por ter sido produzida a partir de uma compreensão emocional prévia.

A análise de Toulmin sobre a imprescindibilidade de se recorrer ao conteúdo da argumentação pode ser determinante para a identificação de decisões frágeis. A análise do conteúdo das premissas pode permitir identificar que o julgador tentou encobrir a real justificativa da decisão tomada, esta que estaria calcada principalmente em razões emocionais.

Uma das principais críticas de Toulmin sobre o modelo silogístico diz respeito ao fato de que, para a construção da premissa maior, a conclusão deveria ser conhecida de antemão ${ }^{18}$. Novamente lembra-se o estudo de Noel Struchiner, pois, ao que parece, decisões baseadas em emoções, ou seja, decisões pré-definidas pelo julgador, que apenas recorre ao direito para justificá-las, são decisões que atenderiam mais facilmente ao método silogístico, isso porque a conclusão já seria preconcebida pelo julgador e, com base nela, ele chegaria na premissa maior ${ }^{19}$.

Buscando combater esse sistema simplista e analisar a força de uma decisão tomando por base o conteúdo das premissas, Toulmin desenvolveu seu modelo de procedimento de análise argumentativa composto por seus elementos principais: dados, alegação, garantia,

\footnotetext{
17 STRUCHINER, Noel. Contexto de descoberta: uma análise filosófica de aspectos psicológicos da argumentação jurídica. In: REIS, Isaac (org.). Diálogos sobre retórica e argumentação. Curitiba, Alteridade, 2018, p.43-59.

${ }^{18}$ TOULMIN, Stephen. The Uses of Argument. Updated Edition. Cambridge: Cambridge University Press, 2003, p. 106.

19 STRUCHINER, Noel. Contexto de descoberta: uma análise filosófica de aspectos psicológicos da argumentação jurídica. In: REIS, Isaac (org.). Diálogos sobre retórica e argumentação. Curitiba, Alteridade, 2018, p.43-59.
} 
apoio, qualificadores modais e condições de refutação ${ }^{20}$. Esses elementos permitiriam verificar, a partir da validade dos argumentos, a aceitabilidade dos discursos ${ }^{21}$.

Como bem sintetiza Ângelo Gamba Prata de Carvalho ${ }^{22}$, a alegação seria o fim do raciocínio interpretativo, o objetivo final de toda argumentação, o argumento central; os dados seriam os fatos aos quais o julgador recorre para justificar a alegação, assemelhandose às "questões de fato"; as garantias seriam afirmações gerais que garantiriam a solidez da argumentação, aproximando-se das "questões de direito"; o apoio seria o aval que se coloca por trás da garantia para certificar sua autoridade; as qualificadoras modais seriam limitações das alegações, enquanto as condições de refutação seriam circunstâncias extraordinárias que poderiam mitigar a forca do argumento ${ }^{23}$.

O que se busca com a aplicação do esquema argumentativo a um recurso extraordinário julgado recentemente pelo Supremo Tribunal Federal é identificar a alegação, ou seja, a conclusão central do julgamento que, em última análise, seria a ratio decidendi, a parte efetivamente vinculante do precedente avaliado.

\subsection{Análise do recurso extraordinário 1.116.949/PR}

\footnotetext{
20 TOULMIN, Stephen. The Uses of Argument. Updated Edition. Cambridge: Cambridge University Press, 2003. Tradução para o português: Os Usos do Argumento. Trad. de Reynaldo Guarani. São Paulo: Martins Fontes, 2001.

21 Importa lembrar do que Toulmin chama de "campodependência", que é justamente um dos pontos diferenciadores entre a sua lógica e a lógica dedutiva, já que, para ele, os argumentos se estruturariam de forma diversa a depender do campo de conhecimento em que são desenvolvidos, por essa razão não seria possível a criação de parâmetros de validade universais. Os tipos de argumentos, como analisa Ângelo Gamba, dependeriam da natureza e das circunstâncias em que cada caso se insere. CARVALHO, Ângelo Gamba Prata de. O esquema de Toulmin e a análise argumentativa de decisões judiciais: perspectivas a partir e além de "Harry nasceu nas Bermudas". In: ROESLER, Claudia; HARTMANN, Fabiano; REIS, Isaac (Orgs.) Retórica e argumentação jurídica: modelos em análise. Curitiba: Alteridade, 2018, p. 48.

${ }^{22}$ CARVALHO, Angelo Gamba Prata de. O esquema de Toulmin e a análise argumentativa de decisões judiciais: perspectivas a partir e além de "Harry nasceu nas Bermudas". In: ROESLER, Claudia; HARTMANN, Fabiano; REIS, Isaac (Orgs.) Retórica e argumentação jurídica: modelos em análise. Curitiba: Alteridade, 2018, p. 45-66.

${ }^{23}$ A síntese do clássico exemplo "Harry nasceu nas Bermudas", exposto pelo próprio Toulmin, ajuda a explicar, na prática, a função de cada um dos elementos. "Harry é um súdito britânico" seria a alegação; "nascer nas Bermudas" seria um dado; o fato de um homem que nasce nas Bermudas ser súdito britânico seria uma garantia; os dispositivos legais que reforçam a garantia seriam o apoio e a possibilidade de seus pais serem estrangeiros e ele ter se naturalizado seria a condição de refutação. O exemplo pode ser mais bem analisado no Capítulo III da obra de Toulmin. TOULMIN, Stephen. The Uses of Argument. Updated Edition. Cambridge: Cambridge University Press, 2003. Tradução para o português: Os Usos do Argumento. Trad. de Reynaldo Guarani. São Paulo: Martins Fontes, 2001.
} 
O entendimento segundo o qual é inadmissível usar em processo penal prova obtida por meio da abertura de correspondência postada nos Correios sem autorização judicial foi fixado pelo Supremo Tribunal Federal em julgamento de recurso extraordinário, com repercussão geral, em sessão virtual ocorrida no dia 18 de agosto de 2020, após análise pelo Plenário da Corte, tendo a maioria acompanhado o voto do Ministro Luiz Edson Fachin ${ }^{24}$.

Conforme extrai-se do relatório do Ministro Marco Aurélio, um policial militar lotado na Coordenadoria Estadual de Defesa Civil, durante o expediente, dirigiu-se ao setor de Protocolo Geral do Palácio Iguaçu/PR, deixando caixa identificada por código Sedex a ser remetida pelo serviço de envio de correspondência da Administração Pública. Servidores públicos responsáveis pela triagem, considerados o peso e o suposto conteúdo da embalagem, abriram-na e constataram a existência de 36 frascos com líquido transparente. Submetido o material a perícia, verificou-se tratar-se de ácido gama-hidroxibutírico e cetamina, substâncias de controle especial.

Importa frisar que o Tribunal de Justiça do Estado do Paraná, julgando recurso interposto contra decisão do Conselho Permanente de Justiça da Comarca de Curitiba, deixou de reconhecer a ilicitude da prova por entender que a garantia constitucional não respalda o cometimento de crimes, além do que o pacote remetido não seria correspondência, mas encomenda.

O recurso foi interposto pelo réu em ação penal que tramitava junto ao Tribunal de Justiça do Estado do Paraná buscando a análise, pela Corte Suprema, sobre se a inviolabilidade constitucional do sigilo de correspondência seria restrita à comunicação epistolar entre pessoas ou se abrangeria encomendas postais.

A Procuradoria-Geral da República, em parecer, opinou pelo desprovimento do recurso por ser o sigilo de correspondência vinculado à liberdade de expressão e livre circulação de ideias, não abrangendo encomendas, ainda que enviadas por meio postal, admitindo-se, em caso de fundadas suspeitas, a abertura de pacotes pelos Correios ou serviços públicos destinados a fins postais sem autorização judicial.

\footnotetext{
${ }^{24}$ Brasil. 2020. Supremo Tribunal Federal. Recurso Extraordinário n. 1.116.949/PR. Inteiro Teor do Acórdão. Relator: Min. Marco Aurélio. Acesso em 12.12.2020. Disponível em: http://redir.stf.jus.br/estfvisualizadorpub/jsp/consultarprocessoeletronico/ConsultarProcessoEletronico.jsf?seq objetoincidente $=5378231$.
} 
O Ministro Relator, em seu voto, entendeu que a garantia da inviolabilidade de correspondência não deixa margem à relativização, salvaguardando, por qualquer modo, o fluxo de comunicações, sendo inadequado o manejo de argumentos metajurídicos (a suspeita quanto ao conteúdo do pacote) para o afastamento da garantia constitucional.

O Ministro Marco Aurélio apresentou voto conciso e simplista, levando o intérprete a crer que, para o Ministro, seria óbvia a conclusão a ser tomada no caso, deixando de lado suas nuances mais complexas. Chegou a mencionar, inclusive, que a discussão sequer existiria se não vivêssemos tempos tão estranhos ${ }^{25}$.

O voto-vogal proferido pelo Ministro Edson Fachin deu-se no mesmo sentido, reconhecendo a ilegalidade da prova. No mérito, porém, foi reconhecida fundamentação distinta. Depois de passar pela Constituição Imperial, o Regulamento dos Telegramas de 1901, e a Constituição de 1967, o Ministro propôs a interpretação da garantia constitucional à luz do Pacto São José da Costa Rica, que determina que ninguém pode ser objeto de ingerências arbitrárias ou abusivas em sua vida privada, na de sua família, em seu domicílio ou em sua correspondência, nem de ofensas ilegais a sua honra ou reputação. Ao fim, propôs a inclusão, na tese, da necessidade de observância às restrições legais, no caso a Lei 6.538/78, que disciplina o serviço postal.

Importa destacar que o Ministro Fachin concluiu que, no caso em análise, não foram respeitadas as cautelas impostas pela Lei 6.538/78, citando trecho do acórdão recorrido que, para ele, tornaria evidente tal constatação. Muito embora fosse essa a questão central de sua argumentação (demonstrar que não foram seguidas as cautelas legais), o Ministro não justificou em que medida e por quais motivos a lei fora desrespeitada.

Entre o voto do Relator e do Ministro Edson Fachin já é possível identificar uma divergência clara na razão fundamental da decisão: para o primeiro, a encomenda postal encontra-se claramente compreendida na garantia constitucional do sigilo de correspondência sendo, portanto, inviolável sem decisão judicial; para o segundo, tal

\footnotetext{
${ }^{25}$ A carência argumentativa, que torna questionável a racionalidade do voto, pode encobrir compreensões prévias do julgador, referentes a seu contexto social, político e emocional, ou seja, é possível que o contexto de descoberta (não exposto) de fato tenha pressionado a justificação da decisão, nos termos do que propôs Noel Struchiner. O Ministro Relator, que criticou em seu voto a utilização de argumentos metajurídicos para a violação da encomenda no caso concreto, pode ele mesmo ter se valido de tais argumentos na construção da decisão. STRUCHINER, Noel. Contexto de descoberta: uma análise filosófica de aspectos psicológicos da argumentação jurídica. In: REIS, Isaac (org.). Diálogos sobre retórica e argumentação. Curitiba, Alteridade, 2018, p.43-59.
} 
garantia constitucional pode ser excepcionada desde que se cumpram as restrições impostas na legislação vigente. Fica claro que, para o Relator, a abertura da encomenda não foi possível porque não havia decisão judicial e para o Ministro Edson Fachin, a ilegalidade da prova se deu pela inobservância das condicionantes previstas na lei que rege o sistema postal.

A Ementa, como se deve imaginar, muito embora devesse sintetizar a decisão tomada pelo colegiado ${ }^{26}$, apresentando um resumo de todos os posicionamentos definidores do resultado final, nem sequer mencionou tal divergência.

O Ministro Alexandre de Moraes proferiu voto que claramente foi construído antes do julgamento colegiado, já que dispunha de divisão em tópicos como se um artigo acadêmico fosse, contendo considerações iniciais, fundamentação e conclusão. Dez doutrinadores nacionais foram citados na fase de fundamentação, até que foi exposto o ponto alto do referido voto: a decisão proferida pelo STF no HC 70.814 em 1994, de relatoria do Ministro Celso de Melo, quando admitiu-se que a inviolabilidade do sigilo epistolar não pode constituir instrumento de salvaguarda de práticas ilícitas, autorizando que a administração penitenciária interceptasse correspondências encaminhadas a sentenciados. Foram citados também outros dois julgamentos mais recentes - um deles proferido no Inq n. 2.424/RJ, em 2010 e o outro no RHC 132.115, em 2018 - que reforçaram o precedente de 1994.

Seguiram-se ainda várias páginas de voto até que o Ministro propusesse a fixação da tese no sentido da licitude da prova obtida por meio da abertura de encomenda postada nos Correios quando houver fundados indícios da prática de atividades ilícitas.

Da análise da decisão judicial proferida, fica claro que, em nenhum momento, o Plenário se preocupou em diferenciar o caso submetido à análise do Tribunal daquele precedente anteriormente firmado, havendo total desconsideração com a linha jurisprudencial anteriormente firmada e com o previsto no artigo 489, $\S 1^{\circ}$, inciso VI, do CPC, que traz em seu bojo o próprio conceito de distinção, noção indispensável ao manejo de precedentes, já que se trata do primeiro passo em sua aplicação ${ }^{27}$.

Durante a sessão virtual do Plenário, a posição do Ministro Marco Aurélio foi acompanhada integralmente pelo Ministro Lewandowski, enquanto a posição do Ministro

\footnotetext{
${ }^{26}$ ROESLER, Entre o paroxismo de razões e a razão nenhuma: paradoxos de uma prática jurídica. Quaestio Iuris, vol. 8, n. 4, 2015, p. 2522.

27 PEIXOTO, Ravi. O sistema de precedentes desenvolvido pelo CPC/2015 - uma análise sobre a adaptabilidade da distinção (distinguishing) e da distinção inconsistente (inconsistent distinguishing). Revista de Processo, São Paulo, SP, v. 248, p. 331-354, out. 2015.
} 
Revista Eletrônica de Direito Processual - REDP.

Rio de Janeiro. Ano 15. Volume 22. Número 2. Maio a Agosto de 2021

Periódico Quadrimestral da Pós-Graduação Stricto Sensu em Direito Processual da UERJ

Patrono: José Carlos Barbosa Moreira (in mem.). ISSN 1982-7636. pp. 670-685

www.redp.uerj.br

Fachin foi seguida pelos Ministros Dias Tóffoli, Carmen Lúcia, Rosa Weber e Gilmar Mendes. Acompanharam o voto vencido os Ministros Luiz Fux e Roberto Barroso.

Para o escopo do presente trabalho importa ainda mencionar que o julgamento do RE 1.116.949/PR foi proferido após reconhecimento de sua repercussão geral e, embora as decisões proferidas pelo Supremo Tribunal Federal no bojo de recursos extraordinários com repercussão geral não tenham sido contempladas pelo rol de precedentes obrigatórios do artigo 927 do CPC, desde há muito, o Tribunal já as reconhece como vinculante ${ }^{28}$.

Vale lembrar que, antes mesmo da promulgação do CPC/15 ou de qualquer discussão sobre se haveria ou não um rol de precedentes vinculantes estabelecido na lei processual, o Supremo Tribunal Federal já conferia caráter vinculante a outras decisões além daquelas proferidas no controle concentrado de constitucionalidade ${ }^{29}$.

\subsection{Aplicação do esquema de Toulmin ao RE 1.116.949/PR}

Após a exposição sintética dos conceitos de ratio decidendi e obiter dictum, da compreensão dos contornos principais do Recurso Extraordinário 1.116.949/PR e da análise do esquema argumentativo de Toulmin, parte-se agora para a aplicação do dito modelo aos votos do Relator, do vogal e do Ministro Alexandre de Moraes, o que fornecerá uma imagem interessante sobre o precedente produzido.

a) Voto do Ministro Marco Aurélio:

\footnotetext{
${ }^{28}$ Sobre esta situação, discorre Odilon Romano neto: "Tal hipótese de vinculação não conta com suporte em disposição constitucional expressa e, não obstante, a partir de uma interpretação sistemática da Constituição e, em especial, da missão por esta conferida ao STF, este passou a compreender que as decisões proferidas nessa seara também se revestem de efeitos vinculantes". ROMANO NETO, Odilon. Modificações na jurisprudência e proteção da confiança. 2016. 576 f. Tese (Doutorado em Direito Processual) - Faculdade de Direito, Universidade do Estado do Rio de Janeiro, Rio de Janeiro, 2016, p. 192.

${ }^{29}$ Importante, neste momento, lembrar de Fredie Didier Júnior, que afirma categoricamente que o CPC/15 inseriu o precedente judicial no processo civil brasileiro e que isso não configura um retrocesso, mas verdadeiro aperfeiçoamento da cultura jurídica, tendência que há muito já se evidencia no sistema: "O CPC/15 inseriu explícita e inequivocamente o precedente judicial na dogmática jurídica processual contemporânea. O que se pretendeu demonstrar com este ensaio é que o recrudescimento da importância do precedente judicial no Direito brasileiro não é um desvirtuamento, senão um aperfeiçoamento, da tradição jurídica com a qual sempre esteve associada o Direito brasileiro. $\mathrm{O}$ atual sistema brasileiro de formação, divulgação, aplicação e superação dos precedentes judiciais não se estabeleceu por acaso, nem fora de uma linha evolutiva cujo início remonta ao final do período colonial brasileiro. Ele é, ao contrário, fruto de uma tradição brasileira que se desenvolveu na prática jurídica e, mais recentemente, no pensamento jurídico brasileiro". DIDIER JUNIOR, Fredie. O respeito aos precedentes como diretriz histórica do direito brasileiro. Revista de Processo Comparado, São Paulo, SP, ano 1. vol. 2, p. 99-120, jul.-dez. 2015, p. 119.
} 
a.1) Dado: A condenação do recorrente tem por base, unicamente, prova relacionada ao disposto no artigo $5^{\circ}$, inciso XII, da Constituição Federal.

a.2) Garantia: artigo $5^{\circ}$, inciso XII, da Constituição Federal.

a.3) Apoio: "Não vivêssemos tempos estranhos seria desnecessário discutir se a inviolabilidade a envolver a intimidade, a privacidade e a livre expressão deve ou não ser flexibilizada" ${ }^{\sharp 0}$. Considera totalmente inadequado manejar argumentos metajurídicos no caso a suspeita quanto ao conteúdo do pacote -, no afastamento de garantia constitucional.

a.4) Alegação (conclusão): A garantia constitucional da inviolabilidade do sigilo da correspondência abrange comunicações entre pessoas, sejam elas realizadas mediante carta, telegrama, pacote ou meio análogo e só pode ser afastada, excepcionalmente, diante de decisão judicial que autorize.

\section{b) Voto do Ministro Edson Fachin:}

b.1) Dado: É necessário que haja previsão legal para eventual restrição da inviolabilidade de correspondência.

b.2) Garantia: $\operatorname{artigo~} 5^{\circ}$, inciso XII, da Constituição Federal e arts. 10 da Lei 6.538/78, Pacto São José da Costa Rica e Pacto Internacional dos Direitos Civis e Políticos.

b.3) Apoio: Cita a Constituição do Império, o Regulamento dos Telegramas de 1901, a Constituição de 1967.

b.4) Alegação (conclusão): Sem autorização judicial ou fora das hipóteses legais, é ilícita a prova obtida mediante abertura de carta, telegrama, pacote ou meio análogo. No caso analisado, a correspondência foi violada porque não se adotaram as cautelas exigidas pelo parágrafo único do art. 10 da Lei 6.538/78.

\section{c) Voto do Ministro Alexandre de Moraes:}

c.1) Dado: nenhuma liberdade individual é absoluta, sendo possível, dentro de certos parâmetros, a interceptação das correspondências e das comunicações.

c.2) Garantia: artigo $5^{\circ}$, inciso XII, da Constituição Federal e arts. 10, III e parágrafo único e 13 , I a IX e $\S 1^{\circ}$, da Lei 6.538/78.

\footnotetext{
${ }^{30}$ Brasil. 2020. Supremo Tribunal Federal. Recurso Extraordinário n. 1.116.949/PR. Inteiro Teor do Acórdão. Relator: Min. Marco Aurélio. Acesso em 12.12.2020. Disponível em: http://redir.stf.jus.br/estfvisualizadorpub/jsp/consultarprocessoeletronico/ConsultarProcessoEletronico.jsf?seq objetoincidente $=5378231$
} 
c.3) Apoio: Cita as lições de 10 doutrinadores nacionais e um importante precedente do STF no sentido da admissibilidade da prova obtida por meio de interceptação de correspondência, desde que presentes indícios de prática de atividades ilícitas.

c.4) Alegação (conclusão): inexistente violação à norma constitucional quando a Administração Pública, respeitados parâmetros que indiquem a presença de elemento razoáveis para suspeitar da prática de atividades ilícitas, abre encomenda postada nos Correios, interceptando o processo de comunicação entre emissor e destinatário.

\section{Conclusões}

Da análise dos principais votos proferidos no julgamento do RE 1.116.949 fica claro que a tese tida como vencedora não foi amplamente debatida pelos julgadores, havendo divergências fundamentais entre aqueles que concordaram com o resultado de provimento do recurso.

Ficou claro também o descaso do Tribunal com a aplicação da linha jurisprudencial consolidada, já que a distinção do caso em comento para o julgamento anteriormente proferido pelo STF sobre a inviolabilidade de correspondência não foi utilizado como técnica de argumentação, o que enfraquece em grande medida a incipiente teoria dos precedentes que se forma no Brasil e até mesmo a compreensão da jurisprudência como um elemento de controle da racionalidade das decisões.

A desconsideração do precedente, se feita de maneira desmedida, vai de encontro aos valores que inspiraram a valorização das decisões judiciais, dentre eles a segurança jurídica, a confiança e a isonomia, valores estes que o legislador colocou como parâmetros para a fundamentação da decisão que supera o precedente judicial. A fundamentação adequada tem o condão de assegurar racionalidade e reduzir a discricionariedade judicial, bem como o decisionismo indesejado. Neste ponto, merece lembrança a concepção de Hermes Zaneti de que o CPC/15 rompeu com a cultura da jurisprudência meramente persuasiva para assumir o papel normativo dos precedentes judiciais, que não se compatibiliza com modificações subjetivas e irracionais ${ }^{31}$.

\footnotetext{
${ }^{31}$ ZANETI JR., Hermes. Precedentes normativos formalmente vinculantes. in DIDIER JUNIOR, Fredie et al.
} (org.). Precedentes, Salvador: Juspodivm, 2015, p. 410. 
Valendo-nos do método proposto por Toulmin e expondo apenas os votos tidos como principais para o debate que se estabeleceu, ficou evidente também que os principais elementos - dados, garantia, apoio, conclusão - não coincidem, não tendo havido empenho dos Ministros em justificar os pontos em que discordam. O layout de Toulmin, ao permitir a identificação das razões de decidir e o cotejo entre os diversos votos, parece ser uma ferramenta determinante para a identificação de um precedente forte.

Não sendo este, porém, o único modelo de análise da racionalidade das decisões, o que se espera é que, com o decorrer dos anos e o fortalecimento de uma cultura de precedentes, os Tribunais de cúpula se comprometam com a justificação racional, já que a racionalidade na construção da decisão judicial é fator determinante para a identificação e aplicação do precedente, sendo indispensável ao controle social dos precedentes formados.

\section{REFERÊNCIAS}

BRASIL. 2020. Supremo Tribunal Federal. Recurso Extraordinário n. 1.116.949/PR. Inteiro Teor do Acórdão. Relator: Min. Marco Aurélio. Acesso em 12.12.2020. Disponível em:

http://redir.stf.jus.br/estfvisualizadorpub/jsp/consultarprocessoeletronico/ConsultarPr ocessoEletronico.jsf?seqobjetoincidente $=5378231$.

CARVALHO, Angelo Gamba Prata de. O esquema de Toulmin e a análise argumentativa de decisões judiciais: perspectivas a partir e além de "Harry nasceu nas Bermudas". In: ROESLER, Claudia; HARTMANN, Fabiano; REIS, Isaac (Orgs.) Retórica e argumentação jurídica: modelos em análise. Curitiba: Alteridade, 2018, p. 45-66.

DAVID, René. Tradução Hermínio A. Carvalho. Os grandes sistemas do direito contemporâneo. 4 ed. São Paulo: Martins Fontes, 2002.

DIDIER JUNIOR, Fredie. O respeito aos precedentes como diretriz histórica do direito brasileiro. Revista de Processo Comparado, São Paulo, SP, ano 1. vol. 2, p. 99-120, jul.-dez. 2015.

DUXBURY, Neil. The nature and authority of precedent. Cambridge: University Press, 2008, 189 p. 
FINE, Toni Jaeger. Introdução ao sistema jurídico anglo-americano. Tradução Eduardo Saldanha. São Paulo: Martins Fontes, 2011.

GOODHART, Arthur. Determining the Ratio Decidendi of a Case. The Yale Law Journal, New Haven, CT, vol. 40, No. 2, p. 161-183, dec. 1930.

GRECO, Leonardo. Garantias fundamentais do processo: o processo justo. In: Estudos de direito processual. Campos dos Goytacazes: Ed. Faculdade de Direito de Campos, 2005, 225-286.

MACÊDO, Lucas Buril. Contributo para definição da ratio decidendi na teoria brasileira dos precedentes judiciais. Revista de Processo, São Paulo, SP, V. 234, ago. 2014, p. 307327.

PEIXOTO, Ravi. O sistema de precedentes desenvolvido pelo CPC/2015 - uma análise sobre a adaptabilidade da distinção (distinguishing) e da distinção inconsistente (inconsistent distinguishing). Revista de Processo, São Paulo, SP, v. 248, p. 331-354, out. 2015.

ROESLER, Entre o paroxismo de razões e a razão nenhuma: paradoxos de uma prática jurídica. Quaestio Iuris, vol. 8, n. 4, 2015, p. 2517-2531.

ROMANO NETO, Odilon. Modificações na jurisprudência e proteção da confiança. 2016. 576 f. Tese (Doutorado em Direito Processual) - Faculdade de Direito, Universidade do Estado do Rio de Janeiro, Rio de Janeiro, 2016.

SANTOS, Paulo Alves. Usando precedentes no layout de argumento proposto por Stephen Toulmin. In: ROESLER, Claudia; HARTMANN, Fabiano; REIS, Isaac (Orgs.) Retórica e argumentação jurídica: modelos em análise. Curitiba: Alteridade, 2018, p. 281-310.

SHECAIRA, Fábio P; STRUCHINER, Noel. Teoria da Argumentação Jurídica. Rio de Janeiro: Editora PUC Rio, 2016.

SILVA, Ovídio Araújo Baptista da. Teoria Geral do Processo Civil. 3 ed. São Paulo: Editora Revista dos Tribunais, 2002.

STRUCHINER, Noel. Contexto de descoberta: uma análise filosófica de aspectos psicológicos da argumentação jurídica. In: REIS, Isaac (org.). Diálogos sobre retórica e argumentação. Curitiba, Alteridade, 2018, p.43-59. 
Revista Eletrônica de Direito Processual - REDP.

Rio de Janeiro. Ano 15. Volume 22. Número 2. Maio a Agosto de 2021

Periódico Quadrimestral da Pós-Graduação Stricto Sensu em Direito Processual da UERJ

Patrono: José Carlos Barbosa Moreira (in mem.). ISSN 1982-7636. pp. 670-685 www.redp.uerj.br

TOULMIN, Stephen. The Uses of Argument. Updated Edition. Cambridge: Cambridge

University Press, 2003. Tradução para o português: Os Usos do Argumento. Trad. de Reynaldo Guarani. São Paulo: Martins Fontes, 2001

TUCCI. Rogério Lauria. Direitos e garantias individuais no Processo Penal Brasileiro. São Paulo: Saraiva, 1993.

ZANETI JR., Hermes. Precedentes normativos formalmente vinculantes. in DIDIER JUNIOR, Fredie et al. (org.). Precedentes, Salvador: Juspodivm, 2015, p. 407-423. 